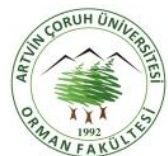

\title{
Yabani kızılcık (Cornus australis L.) odunundan kâğıt üretimi ve kabuğun kâğıt özelliklerine etkisi
}

\section{Paper production from wild dogwood (Cornus australis L.) and the effect of bark on paper properties}

\author{
Ayhan GENÇER ${ }^{1}$, Hasan AKSOY ${ }^{2}$ \\ ${ }^{1}$ Bartın Üniversitesi, Orman Fakültesi, Orman Endüstri Mühendisliği Bölümü, Bartın Türkiye \\ ${ }^{2}$ Sinop Üniversitesi, Ayancık Meslek Yüksekokulu, Sinop, Türkiye
}

\section{Eser Bilgisi / Article Info}

Araştırma makalesi / Research article

DOI: 10.17474/artvinofd.307335

Sorumlu yazar / Corresponding author

Ayhan GENÇER

e-mail: ayhangencer61@ hotmail.com

ORCID: 0000000207585131

Geliş tarihi / Received

20.04.2017

Düzeltme tarihi / Received in revised form

11.09.2017

Elektronik erişim / Online available

26.09.2017

\section{Anahtar kelimeler:}

Cornus australis (L.)

Kraft yöntemi

Kâğıt hamuru

Kabuk

\section{Keywords:}

Cornus australis (L.)

Kraft method

Paper pulp

Bark

\begin{abstract}
Özet
Genellikle kabuk hamur ve kâğıt özelliklerine olumsuz etki yapmaktadır. Bu çalışmada, Kraft yöntemi kullanılarak Yabani kızılcık (Cornus australis L.) odunundan kâğıt hamuru ve deneme kâğıtları üretilmiştir. Pişirme yonga/çözelti oranı $1 / 5$ ve pişirme sıcaklığı $170 \pm 2{ }^{\circ} \mathrm{C}$ sabit alınarak farklı koşullarda yapılmıştır. Kraft metodu $\mathrm{Na}_{2} \mathrm{~S} / \mathrm{NaOH} 18 / 20,18 / 15,18 / 10,18 / 5$ şartlarında gerçekleştirilmiştir. Kabuğun kâğıt hamuru ve kâğıt üretimine olumsuz etkisi olup olmadığını belirlemek için kabuksuz örneklerde en yüksek verimin elde edildiği K2 Pişirmesi kabuklu örneklerle (K5) tekrarlanmıştır. Ayrıca, K2 pişirmesinin maksimum sıcaklığa ulaşma süresi 120 dakikadan 90 dakikaya indirilerek yapılan pişirmede (K6) zaman ve enerji tasarrufu yapılıp yapılanamayacağı irdelenmiştir. Kabuk ölçülen mekanik özellikleri ve hamur verimini olumsuz etkilemiştir. Fakat bu olumsuz etki mekanik özelliklerde \%95 güven aralığında belirgin değildir. Diğer taraftan, kabuk parlaklık özelliklerinde olumsuz, opaklığa olumlu etki etmiştir. Bu etkiler \%95 güven düzeyinde anlamlıdır.
\end{abstract}

\begin{abstract}
Generally bark has a negative effect pulp and paper properties. In this study, paper pulp and hand sheets were produced from Wild dogwood (Cornus australis L.) using Kraft method. The cooking have been different conditions, chip / solution ratio $1 / 5$, cooking temperature $170 \pm 2{ }^{\circ} \mathrm{C}$ by taking constant. Kraft method with the $\mathrm{Na}_{2} \mathrm{~S} / \mathrm{NaOH}, 18 / 20,18 / 15,18 / 10,18 / 5$ performed. Samples were used with and without bark in order to identify the negative impacts of the bark on pulp and paper production. In addition, it has been investigated whether the time of reaching the maximum temperature of $\mathrm{K} 2$ cooking is reduced from 120 minutes to 90 minutes, and the time and energy saving can be made. For all of the mechanical properties that were measured and pulp yield, the bark had a negative effect. But, this effect had not significant on mechanical properties at $95 \%$ significant level. On the other hand the bark had a negative effect on brightness and positive effects on opacity. These effects had significant at $95 \%$ significant level.
\end{abstract}

\section{Giriş}

Yoğun kullanım nedeniyle orman kaynaklarındaki azalma ormanlarımız dışında kalan her türlü lignoselülozik hammaddenin kullanımını zorunlu hale getirmiştir. Bu kaynaklara yıllık bitki artıkları da dâhil edilebilir. Örneğin çivit otu (Istatic tinctoria ve Istatic buschiana) çivit mavisi boyası (Indigo) üretilen bir yıllık bitkidir. İhtiyaç duyulması halinde, bu bitkilerden üretilen kimyasal hamurların iğne yapraklı ağaç odunu hamuru ile karıştırılıp kâğıt üretilmesi durumunda ekonomik bir katkısının olabileceği belirtilmiştir (Çömlekçioğlu vd. 2016). Diğer bir çalışmada Kiwi (Actinidia deliciosa) bitkisinin budama artıklarından Kraft yöntemi ile elde edilen kâğıt hamurunun elenmiş verimi \%44,39 olduğu bildirilmiştir (Gençer 2015). Benzer bir çalışmada, yaygın fındık (Corylus avellena L.) odunundan Kraft metodu ile elde edilen kâğıt hamuru elenmiş veriminin $\% 47,59$ olduğu belirtilmiştir (Gençer ve Özgül 2016). Her iki çalışmada elde edilen elenmiş hamur veriminin yapraklı ağaç odunları ile hamur verimi bakımından rekabet edecek seviyededir.

Yabani kızılcığın Cornus australis (L.) doğal yayılış alanı Avrupa, Kırım, Güney Rusya, İran ve Anadolu'dur. Çoğu diğer meyve türlerinin yetiştirilemediği taşlık, tarımsal açıdan düşük değerde ve kireçli toprak yapısında olan arazilerde doğal olarak yetişebilen bir bitkidir. Ülkemizde 1500 m rakıma kadar yayılış göstermektedir (URL-3 2015).

Ülkemizde baston ve bazı tarımsal ve günlük kullanım araç gereçlerinin saplarının yapımında kullanılan önemli türlerden biri de yabani kızılcıktır. Ancak, bütün gövdeler bu tür kullanımlar için uygun değildir. Ayrıca, bu tür kullanımların artık odunlarının kullanılabileceği bir alan da 
kâğıt endüstrisidir. Endüstriyel boyutta bu tür atıkların, ince odunların ve çalıların kabuklarının soyularak kâğıt hamuru üretiminde kullanılması ekonomik olmayabilir. Yabani kızılcık odunun ağaç işleri sektöründe en yaygın kullanımı 'Devrek Bastonu' yapımıdır. Bu nedenle Orman Genel Müdürlüğünün Zonguldak Devrek İşletme Müdürlüğü bölge esnafına kesim izni vermektedir. Devrek İşletme Müdürlüğü dışındaki diğer birimlerine herhangi bir ETA alınması görülmemektedir. Bu ETA'nın verilme sebebi, hem bu yöredeki el sanatlarının devamını sağlamak hem de kaçak kesimleri önlemektir. Bu yörede üretim yapan küçük atölyelerde üretimden geriye kalan odun ve kabuk artıkları yakacak olarak değerlendirilmekte olup, herhangi bir kaydı tutulmamaktadır.

Çalışmamızda kabukları soyulmuş kızılcık odunundan yapılan 4 pişirme arsında en yüksek verim elde edilen pişirmeler esas alınıp, kabuklu odunlarla aynı şartlarda pişirme yapılarak kabuğun olumsuz etkisi araştırılmıştır.

\section{MATERYAL ve YÖNTEM}

\section{Materyal}

Çalışmada kullanılan Yabani kızılcık (Cornus australis L.) odunu Bartın illi merkez Dallıca köyü, 40 m rakımlı ve Güney batı bakılı bir alandan temin edilmiştir. Kesim, Aralık ayında yapraklar tamamen döküldüğünde yapılmıştır.

\section{Yöntem}

\section{Özgül ağırlık değeri}

Yabani kızılcık odunundan alınan $1 \times 1 \times 1 \mathrm{~cm}^{\prime}$ lik örnekler etüvde $103 \pm 2{ }^{\circ} \mathrm{C}$ ' de sabit ağırlı̆a gelinceye kadar kurutulup, desikatörde soğutulduktan sonra tartılarak tam kuru ağırlık $\left(m_{0}\right)$ değeri bulunmuştur. Daha sonra örnekler parafine daldırılarak yüzeyleri parafin ile kaplanmıştır. Bu yöntemle su alış verişi engellenen örnekler mezura konulan suya daldırılıp taşan hacimden $V_{0}$ değeri bulunmuş ve tam kuru özgül ağırlık $\mathrm{d}_{0}=\left(\mathrm{m}_{0} / \mathrm{V}_{0}\right) \times 100$ eşitliği yardımı ile hesaplanmıştır.

\section{Lif morfolojisine ait ölçme metotları}

Odun örneklerinin maserasyonunda klorit yöntemi kullanılmıştır (Wise ve Jahn 1952). Elde edilen liflerden kalıcı preparatlar hazırlanarak lif ölçümleri ışık mikroskobunda trahe hücresi boyu, lif boyu, lif ve lümen genişliği ölçülmüştür. Lif genişliğinden lümen genişliği çıkartılarak bulunan değer ikiye bölünerek çeper kalınlığı hesaplanmıştır. Lif boyutlarından aşağıdaki eşitlilikler yardımıyla hammaddenin morfolojik olarak kâğıt hamuru üretimine uygunluğu hakkında ön bilgi edinilmiştir.

Elastiklik oranı $=($ Lümen Çapı $\times 100) /$ Lif Genişliği.

Runkel sınıflandırması = (Lif çeper Kalınlığı x 2) / Lümen Çapı

Keçeleşme oranı = Lif Uzunluğu / Lif Genişliği

Katııık katsayısı = (Lif Çeper Kalınlığı x 100) / Lif Genişliği

\section{Kâğıt hamuru pişirme planı}

Bu çalışmada Yabani kızılcık odununun Kraft yöntemi ile kâğıt hamuru üretim şartlarını ortaya koyabilmek için Çizelge $1^{\prime}$ de belirtilen pişirme koşullarında 6 adet Kraft pişirmesi yapılmıştır. Öncelikle kullanılacak $\mathrm{Na}_{2} \mathrm{~S}^{\prime}$ in oranını belirleyebilmek için \%18 $\mathrm{NaOH}$ sabit alınarak kabukları soyulmuş örneklerden $\mathrm{Na}_{2} \mathrm{~S}$ oranı \%20, 15, 10, 5 oranlarında değiştirilerek toplam 4 pişirme yapılmıştır. Yapılan 4 pişirme arasında en yüksek verim elde edilen pişirme (K2) şartları kabuklu odunla (K5) tekrarlanarak kabuğun olumsuz etkisi araştırılmıştır. Ayrıca, K2 pişirmesinin maksimum sıcaklığa ulaşma süresi 120 dakikadan 90 dakikaya indirilerek yapılan pişirmede (K6) zaman ve enerji tasarrufu yapılıp yapılamayacağı irdelenmiştir. Uygulanan pişirme planı Çizelge $1^{\prime}$ de verilmiştir.

Çizelge 1 Kraft yöntemi için uygulanan pişirme planı.

\begin{tabular}{|c|c|c|c|c|c|c|}
\hline P.N & $\mathrm{Y} / \mathrm{Ç}$ & $\mathrm{NaOH}(\%)$ & $\mathrm{Na}_{2} \mathrm{~S}(\%)$ & M.S $\left({ }^{\circ} \mathrm{C}\right)$ & M.S.U.S (dk.) & M.S.P.S (dk.) \\
\hline K1 & $1 / 5$ & 18 & 20 & 170 & 120 & 60 \\
\hline K2 & $1 / 5$ & 18 & 15 & 170 & 120 & 60 \\
\hline K3 & $1 / 5$ & 18 & 10 & 170 & 120 & 60 \\
\hline K4 & $1 / 5$ & 18 & 5 & 170 & 120 & 60 \\
\hline K5 & $1 / 5$ & 18 & 15 & 170 & 120 & 60 \\
\hline K6 & $1 / 5$ & 18 & 15 & 170 & 90 & 60 \\
\hline
\end{tabular}


Kâğıt hamurlarının Kappa numarası ve viskozitesi sırasıyla TAPPI T 236 om-99 ve SCAN-CM 15-62 standartlarına göre yapılmıştır.

\section{Kâğıt hamuru ve deneme kâğıtlarının elde edilmesi}

Pişirme işlemleri elektrik ile ısıtılan, $25 \mathrm{~kg} / \mathrm{cm}^{2}$ basınca dayanıklı, 15 It kapasiteli, dakikada 2 devir yapabilen laboratuvar tipi pişirme kazanında $170 \pm 2{ }^{\circ} \mathrm{C}$ 'de yapılmıştır. Elde edilen hamur yıkandıktan sonra TAPPI T 275 sp-02 standardına göre Somerville tipi sarsıntılı vakum eleğinde elenerek elek artığı ayrılmıştır. Tam kuru yonga ağırlığına göre hamur verimi \% olarak hesaplanmıştır. Elenen hamurlar TAPPI T 200 sp-01 standardına göre Hollander'de $25{ }^{\circ}$ SR'e kadar dövülmüştür. Hamurların serbestlik derecesi Schopper Riegler cihazında ISO 5267-1 standardına göre belirlenmiştir. Dövülmüş hamurlardan ISO 5269-2 standardına göre $75 \pm 2 \mathrm{~g} / \mathrm{m}^{2}$ gramajlı $10^{\prime}$ ar adet deneme kâğıdı yapılmıştır.

\section{Kâğıtların bazı fiziksel, optik ve mekanik özellikleri}

Deneme kâğıtları TAPPI T 402 sp-03 standardına göre $23 \pm 2{ }^{\circ} \mathrm{C}$ sıcaklık ve $\% 50 \pm 2$ bağıl nemde 24 saat kondisyonlandıktan sonra Çizelge 2 'de gösterilen standartlara göre bazı fiziksel, optik ve mekanik özellikleri belirlenmiştir.

\section{İstatistiksel değerlendirme}

Bu çalışmada elde edilen verilerin değerlendirilmesinde SPSS 16.0 paket programı kullanılmıştır. Bu program kullanılarak deneme kâğıtlarının özelliklerinin birbirine etkisini ortaya koyabilmek için çoğul varyans analizi ve varyans analizi yapılmıştır. Gruplar arası farklılı̆ı tespit etmek için ise bu farkın \%95 güven aralığında anlamlı olup olmadığı Duncan testi ile belirlenmiştir. Microsoft Office Çizelge 3 Cornus australis L.odununa ait lif boyutlarının karşılaştırılması.
2010 paket programı kullanılarak aritmetik ortalaması ve standart sapması belirlenmiştir.

Çizelge 2 Kâğıtların bazı fiziksel, optik ve mekanik testlerinde kullanılan yöntemler.

\begin{tabular}{ll}
\hline Deney & Kullanılan yöntem \\
\hline Opaklık & TAPPI T 519 om-02 \\
Parlaklık & TAPPI T 525 om-02 \\
Yırtılma indisi & TAPPI T 414 om-98 \\
Kopma indisi & TAPPI T 494 om-01 \\
Patlama indisi & TAPPI T 403 om-02 \\
\hline
\end{tabular}

\section{BULGULAR}

\section{Cornus australis L. Odununa Ait Özgül Ağırlık Değeri}

Cornus australis L. odunun özgül ağırlık değeri 0,72 $\left(\mathrm{g} / \mathrm{cm}^{3}\right)$ olarak hesaplanmıştır. Bu değerin benzer formda bir bitki olan Yaygın Fındık (Corylus avelliana L.)'da 0,67 $\left(\mathrm{g} / \mathrm{cm}^{3}\right)$ (Gençer ve Özgül 2015) olduğu belirtilmiştir. Benzer şekilde yapraklı ağaçlardan Taxus brevifollia ve iğne yapraklı ağaçlardan Quercus stellata odunlarında $0,67\left(\mathrm{~g} / \mathrm{cm}^{3}\right)$ olduğu bildirilmiştir (Miles ve Smith 2009).

\section{Lif Boyutlarına Ait Bulgular ve Karşılaştırılması}

Cornus australis L. odununa ait kalıcı preparatlar ürerinde ölçülen bazı morfolojik özellikleri ile literatürle karşılaştırılması Çizelge 3'te verilmiştir.

Cornus australis L. odunu lif özellikleri farklı türler ile karşılaştırıldığında; Olea europea L. ile çeper kalınlığı benzer özellik gösterirken lif uzunluğu, lif genişliği ve lümen genişliği daha yüksektir. Lif uzunluğu, lif genişliği, lümen genişliği ve çeper kalınlığı Actinidia deliciosa'dan daha düşüktür. IAWA (1989)'a göre ortalama lif uzunluğu 900-1600 $\mu \mathrm{m}$ arasında olduğu için Yabani Kızılcık'ın “orta uzunlukta" liflere sahip olduğu söylenebilir.

\begin{tabular}{lllll}
\hline Özellikler $(\boldsymbol{\mu m})$ & Cornus australis L. & Corylus avellana L. & Olea europea L. & Actinidia deliciosa \\
\hline Lif uzunluğu & 1173.20 & 1056.29 & 850 & 1583.9 \\
Lif genişliği & 16.20 & 23.76 & 15.1 & 35.97 \\
Lümen genişliği & 11.52 & 14.08 & 6.2 & 22.30 \\
Çeper kalınlığı & 6.70 & 4.80 & 4.5 & 6.84 \\
Trahe uzunluğu & 645.13 & 599.98 & - & - \\
\hline
\end{tabular}

Cornus australis L. (Tespit); Corylus avellana L. (Merev 1998); Olea europea L. (Ververis vd. 2004); Actinidia deliciosa (Yaman ve Gençer 2005) 
Yabani Kızılcık (Cornus australis L.) Liflerinin Morfolojik Özelliklerinin Kâğıdın Bazı Fiziksel ve Mekanik Özellikleri Üzerine Etkisi

Cornus australis L. odununa ait lif boyutları arasındaki ilişki Çizelge 4'te verilmiştir. Actinidia deliciosa'nın (Yaman ve Gençer 2005) değerleri ile karşılaştırıldığında Elastiklik katsayısı hariç diğer değerler Cornus australis L.'de daha yüksek çıkmıştır.
Elastiklik katsayısı $50-75$ arasında olan ve $0.55-0.70 \mathrm{~g} / \mathrm{cm}^{3}$ arasında orta yoğunluğa sahip odunlar bu gruba girmektedir. Bu grupta çeper kalınlıkları biraz fazla olmalarına karşın, lümen boşlukları da geniş olduğu için kâğıt yapımı sırasında kısmen ezilip direnç özellikleri iyi olan kâğıtlar verirler (Bostancı 1987). Corylus avellana L. bu özellikleri ile esnek lifler sınıfına girer ve iyi bir yüzey bağlantısı sağlayabileceği varsayılabilir.

Çizelge 4 Cornus australis L. odununa ait lif boyutları arasındaki ilişkiler ve karşılaştırılması.

\begin{tabular}{lll}
\hline Özellikler & Cornus australis L. & Actinidia deliciosa \\
\hline Elastiklik Katsayısı & 51.88 & 61.99 \\
Rijidite Katsayısı & 30.18 & 19.00 \\
Runkel Oranı & 1.16 & 0.61 \\
Keçeleşme Oranı & 52.84 & 44.03 \\
\hline
\end{tabular}

Cornus australis L. (Tespit); Actinidia deliciosa (Yaman ve Gençer 2005)

\section{Kâğıt Hamuru ve Deneme Kâğıtlarına Ait Bulgular}

Cornus australis L. odunundan kraft yöntemiyle elde edilen kâğıt hamurlarının elenmiş verimi, elek artığı, toplam verimi, Kappa numarası ve viskozitesi Çizelge 5 'te verilmiştir. Çizelge 5 incelendiğinde Cornus australis L. odunundan kraft yöntemiyle elde edilen kağıt hamurlarının elenmiş verimi, elek artı̆̆ı, toplam verimi,
Kappa numarası ve viskozitesi incelendiğinde en yüksek elenmiş verim K2 (\%40.59), en düşük Kappa numarası K1 (\%24.25) ve en yüksek viskozite K5 (1240.31 $\left.\mathrm{cm}^{3} / \mathrm{g}\right)$ numaralı pişirmelerde tespit edilmiştir. Schild vd. (2010) yaptıkları çalışmada okaliptüs yongalarından Kraft yöntemi ile elde edilen hamurlarda kappa numarasını 14.6 ve viskoziteyi $1240 \mathrm{~cm}^{3} / \mathrm{g}$ olarak tespit etmişlerdir.

Çizelge 5 Cornus australis L. odunundan kraft yöntemiyle elde edilen kağıt hamurlarının elenmiş verimi,elek artığı,toplam verimi,kappa numarası ve viskozitesi.

\begin{tabular}{lccccc}
\hline P.N. & Elenmiş verim (\%) & Elek artığı (\%) & Toplam verim (\%) & Kappa no & Viskozite $\left(\mathbf{c m}^{\mathbf{3}} \mathbf{/ g}\right)$ \\
\hline K1 & 39.87 & 5.88 & 45.75 & 24.25 & 1230.00 \\
K2 & 40.59 & 7.18 & 48.77 & 24.70 & 1240.28 \\
K3 & 38.77 & 8.20 & 45.77 & 25.20 & 1050.00 \\
K4 & 38.38 & 9.67 & 48.05 & 24.90 & 844.17 \\
K5 & 40.12 & 9.31 & 50.30 & 25.34 & 1240.31 \\
K6 & 38.41 & 12.6 & 51.01 & 28.74 & 950.46 \\
\hline
\end{tabular}

Kraft Yöntemiyle Elde Edilen Deneme Kâğıtlarına Ait Bulguların Değerlendirilmesi

Kraft yöntemi ile elde edilen kâğıtların bazı optik, mekanik özellikleri Çizelge 6'da verilmiştir. Çizelge 6 incelendiğinde aynı sütundaki aynı harfler \%95 güven aralığında farkların istatistiksel olarak anlamsız olduğunu göstermektedir.
Çizelge 6 Kabuksuz Cornus australis L. odunundan 180 dakikada elde edilen deneme kâğıtlarının bazı optik ve mekanik özellikleri

\begin{tabular}{lllll}
\hline Özellikler & K1 & K2 & K3 & K4 \\
\hline Opaklık (\%) & $99.65 a b$ & $99.67 b$ & $99.55 a$ & $99.72 \mathrm{c}$ \\
Parlaklık (\%) & $22.15 \mathrm{a}$ & $22.03 \mathrm{a}$ & $23.11 \mathrm{~b}$ & $23.65 \mathrm{~b}$ \\
Yırtılma indisi (mN. m²/g) & $5.07 \mathrm{ab}$ & $5.14 \mathrm{ab}$ & $5.01 \mathrm{a}$ & $5.17 \mathrm{ab}$ \\
Kopma indisi (N.m/g) & $86.57 \mathrm{ab}$ & $93.66 \mathrm{bc}$ & $81.60 \mathrm{a}$ & $86.04 \mathrm{ab}$ \\
Patlama indisi (kPa. m²/g) & $3.65 \mathrm{a}$ & $3.89 \mathrm{a}$ & $3.85 \mathrm{a}$ & $3.45 \mathrm{a}$ \\
\hline
\end{tabular}


Çizelge 5'deki pişirmelerin en yüksek verim elde edilen (K2) şartlarda örnekler kabuksuz örneklerde sürenin 30 dakika azaltılması ile yapılan pişirmelerden elde edilen kâğıtların bazı optik, mekanik özellikleri Çizelge 7'de verilmiştir. Çizelge 7 incelendiğinde opaklık değeri hamur pişirme süresinin kısalması ile azalmış, patlama, kopma ve yırtılma indisleri artmıştır ancak her iki durumda da \%95 güven aralığında farkların istatistiksel olarak anlamsızdır. Parlaklık değeri sürenin kısalması ile anlamlı olarak artmıştır.

Çizelge 7 Sürenin kabuksuz odundan elde edilen kâğıtların bazı optik ve mekanik özelliklerine etkisi

\begin{tabular}{lll}
\hline Özellikler & Kabuksuz 180 dk. (K2) & Kabuksuz 150 dk. (K5) \\
\hline Opaklık (\%) & $99.67 \mathrm{a}$ & $99.68 \mathrm{a}$ \\
Parlaklık (\%) & $22.03 \mathrm{a}$ & $21.74 \mathrm{~b}$ \\
Yırtılma indisi $\left(\mathrm{mN} . \mathrm{m}^{2} / \mathrm{g}\right)$ & $5.14 \mathrm{a}$ & $5.11 \mathrm{a}$ \\
Kopma indisi $(\mathrm{N} . \mathrm{m} / \mathrm{g})$ & $93.66 \mathrm{a}$ & $93.21 \mathrm{a}$ \\
Patlama indisi (kPa. m²/g) & $3.89 \mathrm{a}$ & $4.01 \mathrm{a}$ \\
\hline
\end{tabular}

Kabuğun kâğıt özelliklerine etkisini belirlemek için Çizelge $6^{\prime}$ daki pişirmelerin en yüksek verim elde edilen (K2) şartlarda örnekler kabuklu örneklerde aynı pişirme süresi ile yapılan pişirmelerden elde edilen kâğıtların bazı optik, mekanik özellikleri Çizelge $8^{\prime}$ de verilmiştir. Çizelge 8 incelendiğinde Cornus australis L. odunundan kabuklu ve kabuksuz örneklerde yapılan pişirmeler incelendiğinde kabuklu örneklerde opaklık değeri anlamlı bir şekilde artmış, parlaklık değeri anlamlı bir şekilde azalmış, kopma, patlama ve yırtılma indisleri azalmış ancak, azalma \%95 güven aralı̆ı̆ıda istatistiksel olarak anlamsızdır. Benzer bir çalışmada Kraft yöntemi ile kiwi bitkisinin budama artıklarından kabuklu ve kabuksuz olarak iki ayrı hamur elde edilmiştir. Bu hamurlar 35 @SR'e kadar dövüldüğünde kabuklu örneklerden yapılan deneme kâğıtlarının yırtılma indisi, kopma uzunluğu ve patlama indisi değerlerinin kabuksuz örneklere göre azaldığı ve bu azalmanın \%95 güven aralığında önemli olduğu belirtilmiştir. Bu nedenle kabuklu örneklerden elde edilen hamurlardan torba kâğıdı, ambalaj kâğıdı ve mukavva üretilmesi önerilmemiştir (Gençer 2015).

Çizelge 8 Kabuğun kâğıdın bazı optik ve mekanik özelliklerine etkisi

\begin{tabular}{lll}
\hline Özellikler & Kabuksuz 180 dk. (K2) & Kabuklu 180 dk. (K6) \\
\hline Opaklık (\%) & $99.67 \mathrm{a}$ & $99.68 \mathrm{~b}$ \\
Parlaklık (\%) & $22.03 \mathrm{a}$ & $18.06 \mathrm{~b}$ \\
Yırtılma indisi $\left(\mathrm{mN} . \mathrm{m}^{2} / \mathrm{g}\right)$ & $5.14 \mathrm{a}$ & $5.12 \mathrm{a}$ \\
Kopma indisi $(\mathrm{N} . \mathrm{m} / \mathrm{g})$ & $93.66 \mathrm{a}$ & $93.21 \mathrm{a}$ \\
Patlama indisi $\left(\mathrm{kPa} . \mathrm{m}^{2} / \mathrm{g}\right)$ & $3.89 \mathrm{a}$ & $4.01 \mathrm{a}$ \\
\hline
\end{tabular}

\section{TARTIŞMA ve SONUÇ}

Cornus australis L. odunun özgül ağırlık değeri 0,72 $\left(\mathrm{g} / \mathrm{cm}^{3}\right)$ olarak hesaplanmıştır. Kâğıt hamuru üretiminde özgül ağırlığı yüksek olan odunlar yongalama sırasında yüksek enerji tüketimi ve yongalayıcı bıçaklarının körelme sıklığını artırdıklarından öncelikli olarak tercih edilmezler. Ancak, kazan kapasitesini etkin kullanma bakımından özgül ağırlık değerinin artması, birim kazan hacmine yüklenecek yonga miktarını ve buna bağıı olarak pişirme sonunda hamur miktarını arttırdığı belirtilmiştir (KırCl, 2000). Bu bakımdan Cornus australis L. odunundan kağıt hamuru üretirken yüksek özgül ağırlık değeri olumlu etki göstermektedir. Lignoselülozik bir hammaddenin kâğıt hamuru üretimine uygunluğunun belirlenmesinde en önemli morfolojik özelliklerden biri lif uzunluğudur. Cornus australis L. odunun lif uzunluğu IAWA (1989) sınıflandırmasına göre orta uzunlukta lif grubuna dâhil edilebilir. Bu grup lifler yapraklı ağaç lif uzunluklarına benzer özelliktedir. Bu nedenle kâğı̆t üretiminde yapraklı ağaç odunları yerine ikame olarak kullanılabilir.

Yapılan 4 pişirmede en yüksek elenmiş verim \% $15 \mathrm{Na}_{2} \mathrm{~S}$ ve $\% 18 \quad \mathrm{NaOH}$ şartlarında $\mathrm{K} 2$ pişirmesinde gerçekleştirilmiştir. Buna göre \% $20 \mathrm{Na}_{2} \mathrm{~S}$ oranı yüksek olduğu söylenebilir. Bunu aynı şartlarda elek artığının da azalması desteklemektedir. \%15 den sonra elenmiş verimin azalması ve elek artığının artması $\% 10$ ve $\% 5 \mathrm{Na}_{2} \mathrm{~S}$ oranının yetersiz olduğunu göstermektedir. Kraft pişirmelerinde $\mathrm{Na}_{2} \mathrm{~S}$ oranı hamur verimine olumlu etki 
yapsa da $\mathrm{K} 1$ pişirmesinde $\% 20 \mathrm{Na}_{2} \mathrm{~S}$ kullanılması elenmiş verimi olumsuz etkilemiştir. \%20 $\quad \mathrm{Na}_{2} \mathrm{~S}^{\prime}$ de Kappa numarasının en düşük sevide çıkması delignifikasyonun en yüksek olduğunu elek artığının en düşük olması da yüksek konsantrasyondan dolayı hammadde kayıplarına neden olduğunu göstermektedir. Maksimum sıcaklığa ulaşma süresi 120 dakikadan 90 dakikaya indirildiğinde parlaklık değeri dışındaki özelliklerdeki değişim \%95 güven aralığında anlamsız olduğundan zaman ve enerji tasarrufu sağlamak için bu süre ideal sayılabilir.

Bu durumda Cornus australis L. odunundan Kraft yöntemi ile kağıt hamuru üretiminde optimum şartlar;

$\mathrm{NaOH}$ oranı:\%18

$\mathrm{Na}_{2} \mathrm{~S}: \% 15$

Yonga/ Çözelti oranı: $1 / 5$

Maksimum Sıcaklık:170 $\left({ }^{\circ} \mathrm{C}\right)$

Maksimum Sıcaklığa Ulaşma Süresi: $90 \mathrm{dk}$.

Maksimum Sıcaklıkta Pişirme Süresi: 60 dk. olarak kabul edilebilir.

Kabuğun elenmiş hamur verimini ve viskozitesini düşürdüğü ve Kappa numarasını artırdığı tespit edilmiştir. Kabuk bu yönleri ile hamur verim ve kalitesine olumsuz etki etmektedir. Ayrıca, kâğıdın mekanik ve optik özelliklerini düşürdüğü, mekanik özelliklerinde fark \%95 güven düzeyinde anlamsız olduğu, ancak optik özelliklerde anlamlı olduğu belirlenmiştir. Bu nedenlerle üretilecek kâğıt türüne göre kabuklu veya kabuksuz örnek kullanılmasına karar verilmelidir.

Yabani kızılcık (Cornus australis L.)'nin kâğıt hamuru özellikleri tam olarak belirlemek için diğer hamur üretim yöntemlerinin de araştırılması gerektiği kanaatindeyiz.

\section{TEŞEKKÜR}

Bartın Üniversitesi Bilimsel Araştırma Projeleri Komisyonu tarafından desteklenmiştir. (Proje No: 2014-FEN-C-006)

\section{KAYNAKLAR}

Bostancı Ş (1987) Kâğıt Hamuru Üretimi ve Ağartma Teknolojisi. Karadeniz Üniversitesi Orman Fakültesi Karadeniz Üniversitesi Basımevi Genel Yayın No:114 Fakülte Yayın No: 13 Trabzon.

Cömlekcioglu N, Tutus A, Cicekler M, Canak A, Zengin G (2016) Investigation of Isatis Tinctoria and Isatis Buschiana Stalks as Raw
Materials for Pulp and Paper Production. Drvna Industrija 67(3): 249-255.

Gençer A (2015) The utilization of Kiwi (Actinidia deliciosa) Prunings Waste for Kraft Paper and the Effect of the Bark on Paper Properties. Drewno 58 (194): 103-113.

Gençer A, Özgül U (2015) Yaygın Fındık (Corylus avellana L.) Odunundan Soda Yöntemi İle Kâğıt Hamuru Üretim Parametrelerinin Belirlenmesi. Turkish Journal of Forestry, 16(2):159-163.

Gençer A, Özgül U (2016) Utilization of Common Hazelnut (Corylus avellana L.) Prunings for Pulp Production. Drvna Industrija 67 (2): 157-162.

IAWA Committee (1989) IAWA list of microscopic features for hardwood identification IAWA Bulletin n.s., 10: 219-332.

ISO 5267-1 (2012) Pulps- Determination of Drainability Part I: Schopper Reigler Method

ISO 5269-2 (2013) Pulps preparation of laboratory sheets for physical testing. Part 2: Rapid-Köthem method.

Kırcı H (2000) Kâğıt Hamuru Endüstrisi. Ders Notları, Karadeni Teknik Üniversitesi Orman Fakültesi Yayınları,Yayın No:63

Merev N (1998) Odun Anatomisi Cilt 1 Doğu Karadeniz Bölgesindeki Doğal Angiospermae Taksonlarının Odun Anatomisi. Genel Yayın No: 189 Fakülte Yayın No: 27 Karadeniz Teknik Üniversitesi Matbaası Trabzon.

Miles P D, Smith W B (2009) Specific Gravity and Other Properties of Wood and Bark for 156 Tree Species Found in North America. Res. Note NRS-38. Newtown Square, PA: U.S. Department of Agriculture, Forest Service, Northem Research Station. 35p.

SCAN-CM 15-62 Viscosity of Cellulose

Schild G, Sixta H, Testova L (2010) Multifunctional Alkaline Pulping, Delignification and Hemicellulose Extraction. Cellulose Chemistry and Technology, 44 (1-3):35-45.

TAPPI 403 om-02 (2002) Bursting strength of paper

TAPPI 414 om-98 (1998) Internal tearing resistance of paper (Elmendorf-type method)

TAPPI T 236 om-99 (1999) Kappa number of pulp

TAPPI T 402 sp-03 [2003]Standard conditioning and testing atmospheres for paper, board, pulp handsheets, and related products

TAPPI T 402 sp-03(2003) Standard conditioning and testing atmospheres forpaper, board, pulp handsheets, and related products

TAPPI T200 sp-01 (2001) Laboratory beating of pulp (Valley beater method)

TAPPI T275 sp-02 (2002) Screening of pulp (Somerville-type equipment)

TAPPI T494 om-01 (2001) Tensile Properties of Paper and Paperboard (Using Constant Rate of Elongation Apparatus)

TAPPI T519 om-02 (2002) Diffuse Opacity of Paper (d/0 paper backing)

TAPPI T525 om-02 (2002) Diffuse Brightness of Pulp (d/0)

URL-3 (2015). http://balcikhisar-der.tr.gg/ANA-SAYFA.htm.

Ververis C, Georghiou K, Christodouulakis N, Santas P, Santas R (2004) Fiber dimensions, lignin and cellulose of various plant materials and their suitability for paper production. Industrial Crops and Products 19 (3): 245-254

Wise LE, Jahn C (1952) Wood Chemistry. $2^{\text {nd }}$ Edition Vol 1-2 Reinhold Publication Co. New York U.S.A.

Yaman B, Gençer A, (2005) Trabzon koşullarında yetiştirilen kiwi (Actinidia deliciosa (A.Chev.) C. F. Liang\& A. R. Ferguson)' nin morfolojisi. Süleyman Demirel Üniversitesi Orman Fakültesi Dergisi A (2): 149-155. 